\title{
Introdução do conceito de derivada a partir da Investigação Matemática
}

\author{
Introduction of the concept of derivative from Mathematical Investigations
}

\begin{abstract}
Allan Silva Ferreira ${ }^{1}$
Elenice de Souza Lodron Zuin ${ }^{2}$
\end{abstract}

\section{Resumo}

Neste artigo, apresentamos um recorte da pesquisa realizada no Mestrado Profissional em Ensino de Ciências e Matemática da PUC Minas, a qual possibilitou a elaboração do nosso produto educacional intitulado "A derivada e suas diferentes abordagens: uma proposta para a introdução do seu conceito". Este se constituiu em um caderno de atividades destinado aos professores de Cálculo Diferencial e Integral. Nosso intuito foi possibilitar o ensino e aprendizagem da derivada sob as abordagens algébrica e geométrica, aliadas à História da Matemática. As atividades foram concebidas tendo como premissa a metodologia da Investigação Matemática, integrando o aplicativo móvel Geogebra, e a sugestão de vídeos disponíveis no YouTube.

Palavras-chave: Educação matemática. Cálculo Diferencial. Conceito de derivada. Aplicativo móvel. História da Matemática.

\begin{abstract}
In this paper, we present a review of the research developed in the Master's Degree in Science and Mathematics Teaching at Pontifícia Universidade Católica de Minas Gerais, Brazil, which enabled the elaboration of our educational product "The derivative and its different approaches: a proposal for the introduction of its concept". This is a guide with activities for teachers of Differential and Integral Calculus. Our intention is to enable the teaching and learning of the derivative under the algebraic and geometric approaches, allied to the History of Mathematics. The activities were elaborated based on the methodology of Mathematical Investigations, associating the mobile app Geogebra, and the suggestion of videos available on YouTube.
\end{abstract}

Keywords: Mathematics education. Differential Calculus. Derivative concepts. Mobile app. History of Mathematics

1 Mestre em Ensino de Ciências e Matemática pela PUC Minas, Docente do Centro Universitário Newton Paiva. e-mail: prof.allan.bh@gmail.com

2 Doutora em Educação Matemática pela PUC SP e Universidade de Lisboa, Docente do Programa de Pós-Graduação em Ensino de Ciências e Matemática da PUC Minas, Membro do Grupo Pesquisa de História da Educação Matemática no Brasil. e-mail: elenicezuin@gmail.com 


\section{Introdução}

O Cálculo Diferencial e Integral assume um grau de importância nas Ciências Exatas e outras áreas do conhecimento devido à sua vasta aplicação. Diversos cursos possuem o Cálculo Diferencial e Integral (CDI) em suas grades curriculares. Alguns estudos recentes, como de Wrobel, Zeferino e Carneiro (2013) e Garzella (2013) evidenciam problemas em relação ao aproveitamento dos alunos, indicando que, ao longo dos anos, vem aumentando o índice de reprovação e desistência dessa disciplina. Para Igliori (2009, p. 13), o Cálculo tem "uma condição privilegiada na formação do pensamento avançado em Matemática" e, na graduação, é "um dos grandes responsáveis pelo insucesso dos estudantes". Esses fatores colaboram para a evasão no Ensino Superior.

Em nossa experiência profissional, também constatamos os mesmos problemas apontados pelos pesquisadores e, a cada conversa informal com outros professores que lecionam a disciplina, atestando o baixo desempenho dos alunos, foi se manifestando em nós o desejo de contribuir para o ensino e aprendizagem de um conceito importante que é o de derivada. Esse é um tópico que, via de regra, é introduzido através de aulas expositivas, sem que o professor compartilhe, com os alunos, aspectos históricos do desenvolvimento do Cálculo Diferencial e Integral e sem fazer muitas contextualizações. Em relação a esse último ponto, encontramos Barbosa (2004, p. 11), que recrimina essa postura, dizendo: "O Cálculo pelo cálculo, sem aplicação e contextualização, fica centrado em uma pedagogia rotineira, tradicional, em que muitos docentes estão acostumados". Constatamos que, muitos docentes introduzem o conceito de derivada se apoiando em definições formais e interpretação geométrica - não necessariamente nesta ordem - prosseguindo com as regras de derivação e, muitas vezes, seguem-se as intermináveis e cansativas listas de exercícios de fixação. Tudo isso ocorrendo de forma mecânica, dentro de um ensino tradicional. Essa também é a visão de Reis (2009), destacando ainda que, com essa 
metodologia, os alunos se fixam mais nas operações algébricas e memorização de fórmulas do que no entendimento dos conceitos.

Realizamos entrevistas com professores universitários com mais de quinze anos de efetiva atuação como docentes de CDI. Nossos objetivos foram verificar quais eram as suas metodologias para introduzirem o conceito de derivada nos cursos de graduação; se realizavam abordagens históricas; quais livros-texto utilizavam na preparação de suas aulas; se empregavam outros recursos pedagógicos e/ou algum recurso tecnológico. As entrevistas revelaram que, nem sempre, esses docentes tratavam de aspectos históricos relativos ao CDI, com a justificativa de que essa omissão se devia à grande extensão do programa a ser cumprido na disciplina. Averiguamos que os entrevistados não recorrem às TICs, não utilizam vídeos, nem programas computacionais. Entretanto, todos afirmaram trabalhar o conceito de derivada sob as perspectivas das abordagens algébrica e geométrica em suas aulas, procurando realizar algumas contextualizações.

Pretendendo verificar quais aspectos os estudantes apreenderam sobre 0 tópico derivada, aplicamos um questionário com três perguntas, para uma turma de 64 alunos, ao final do semestre da disciplina Cálculo Diferencial e Integral I, de um curso de Ciências Exatas de uma instituição superior de Belo Horizonte. Analisando as suas respostas, constatamos que poucos alunos realmente assimilaram o conceito de derivada de maneira correta. A maioria fazia a associação de derivada a um algoritmo, a um processo algébrico, sem conseguir explicitar "o que é a derivada" ou indicar alguma de suas aplicações.

As respostas desses alunos reforçaram, em nós, o desejo de elaborar um guia que interviesse de forma propositiva na prática docente quanto ao ensino de derivada, principalmente em relação ao seu aspecto conceitual.

As palavras de Chervel vieram ao encontro das nossas perspectivas:

Ensinar (enseigner) é, etimologicamente, "fazer conhecer pelos sinais". É fazer com que a disciplina se transforme, no ato pedagógico, em um conjunto significante que terá como valor representá-la, e por função torná-la assimilável. (CHERVEL, 1990, p.192). 
Decidimos, então, desenvolver um material direcionado aos professores de Cálculo Diferencial e Integral I, que culminou em um caderno de atividades intitulado "A derivada e suas diferentes abordagens: uma proposta para a introdução do seu conceito", se constituindo no produto educacional integrado à dissertação "Diferentes abordagens do conceito de derivada: uma proposta de Investigação Matemática"3, cumprindo os requisitos do Mestrado Profissional em Ensino de Ciências e Matemática da PUC Minas. Neste artigo, apresentaremos, de forma sucinta, o material elaborado, discorreremos sobre a aplicação do mesmo para um grupo de alunos e apresentaremos os resultados obtidos.

\section{Outros trabalhos e direcionamentos para nosso produto educacional}

$\mathrm{Na}$ revisão de literatura, encontramos o estudo de Bisognin \& Bisognin (2011), que realizaram uma pesquisa tendo como objetivo investigar quais eram as dificuldades de alunos, de um curso de mestrado em Ensino de Matemática, em analisar e interpretar as informações explicitadas na representação gráfica de funções ou de suas derivadas primeira e segunda e relacioná-las. Concluíram que as dificuldades apresentadas pelos participantes, no tocante ao conceito de derivada, se deviam ao fato de os mesmos não estabelecerem as devidas conexões entre as representações gráficas e analíticas, afirmando que a maioria dos participantes apresentou "problemas em termos de conhecimentos dos conceitos de derivada de funções a partir de uma perspectiva gráfica". (p. 523).

"Compreensões de Conceitos de Cálculo Diferencial no Primeiro ano de Matemática - uma abordagem integrando oralidade, escrita e informática", tese de doutorado de Olímpio (2006), é outro trabalho relevante. O pesquisador investigou compreensões emergentes sobre os conceitos de função, limite,

\footnotetext{
3 Trabalhos desenvolvidos por Allan Silva Ferreira, sob orientação da Profa. Dra. Elenice de Souza Lodron Zuin e coorientação da Profa. Dra. Lídia Maria Luz Paixão Ribeiro de Oliveira.
} 
continuidade e derivada produzidos por alunos iniciantes num curso de Matemática. O autor, realizando um estudo com oito estudantes, constatou que os conflitos emergentes poderiam ter suas raízes numa compreensão limitada do conceito de função. Os resultados dessa pesquisa sugerem uma maior e mais intensiva exploração da natureza dinâmica do Cálculo Diferencial.

$\mathrm{Na}$ dissertação de mestrado "Uma proposta para o ensino do conceito de derivada no ensino médio", André (2008) teve como objetivo desenvolver, nos alunos daquele nível, a ideia inicial de variação de uma função, seguida dos conceitos de variação média, variação instantânea, até chegar ao conceito de derivada. Os resultados obtidos sugerem que a abordagem utilizada enriqueceu as imagens de conceito dos alunos tornando o estudo de derivada viável para estudantes do Ensino Médio, tendo como pré-requisito o estudo de função.

Lima (2012), em sua dissertação de mestrado intitulada "Introduzindo o conceito de Derivada a partir da ideia de variação", objetivou elaborar, aplicar e analisar uma sequência didática que possibilitasse a construção do conceito de derivada. $O$ autor inferiu que os resultados obtidos na pesquisa realizada com alunos que iniciavam o curso de Cálculo Diferencial, indicavam que a maior parte dos discentes havia chegado ao conceito de derivada como uma medida de variação e que aplicação da sequência didática proposta, sem fazer uso das aulas expositivas, colaborou para que os estudantes tivessem outro posicionamento, desvencilhando-se do modelo passivo de ser apenas receptor de conhecimentos.

Os trabalhos mencionados nos conduziram a reflexões sobre as deficiências dos alunos subjugados a uma metodologia de ensino que segue uma perspectiva tradicional. Para efetivar nossa investigação, buscamos compreender como os autores dos principais livros-texto de Cálculo introduziam a derivada em suas obras. Dentre os livros adotados ou utilizados para preparar as aulas, citados pelos professores entrevistados e por colegas, selecionamos cinco obras que têm ou tiveram grande circulação nas principais instituições de Ensino Superior no Brasil. Esta análise foi primordial para verificarmos como os autores desenvolviam o tópico derivada, como introduziam a temática, se evidenciavam 
aspectos históricos, se havia contextualização no decorrer do texto ou na proposição de exercícios.

Todos estes aspectos nos encaminharam para a elaboração de um caderno de atividades, destinado aos professores de CDI, partindo de uma metodologia que se pauta na Investigação Matemática, seguindo a perspectiva aventada por Ponte, Brocardo e Oliveira (2013), em um primeiro momento, mas também ancorada nos trabalhos de Brocardo (2001), Ponte (2003) e Frota (2013).

Outra proposta, que consideramos propícia para ser desenvolvida, lado a lado com a Investigação Matemática, foi a elaboração de atividades relacionadas às TICs - Tecnologias da Informação e Comunicação - especificamente, quanto ao uso de Smartphones, com a utilização do aplicativo Geogebra. Defendemos que "as abordagens históricas podem propiciar um melhor esclarecimento dos conceitos e teorias." (ZUIN, 2003). Neste sentido, em um primeiro momento, nos centramos em vídeos, disponíveis no YouTube, para promover discussões relativas aos aspectos históricos do desenvolvimento do CDI e oportunizar aos alunos outros pontos de vista e percepções sobre as aplicações da derivada.

\section{Alguns pontos sobre a Investigação Matemática}

Há mais de dez anos, os estudos de Frota (2006) já apontavam que alguns problemas com o ensino/aprendizagem de CDI estavam relacionados "a fatores decorrentes, em parte, de um ensino universitário de massa: excessivo número de alunos, grande parte deles desmotivada, ou apresentando lacunas na formação matemática básica”. Questionamentos desta autora sobre as mudanças que deveriam ocorrer para se promover um ensino/aprendizagem de qualidade:

Como penetrar a sala de aula, em particular a sala de aula de Cálculo, rompendo com uma certa inércia dominante que a torna improdutiva, tanto para o professor, quanto para o aluno? A resposta a essa questão demanda um movimento por parte de professores e alunos, no sentido de criação de um novo ambiente de aprendizagem em sala, o que representa uma alteração substancial dos papéis do professor e do aluno. (FROTA, 2006, p. 2). 
É notório que, normalmente, as aulas de Matemática são centradas no professor, que expõe os conteúdos na lousa ou utiliza o projetor multimídia. $O$ docente "passa o conhecimento", faz demonstrações, expõe propriedades e regras, muitas vezes, sem oportunizar algum tipo questionamento ou permitir interferência dos alunos. Sob essas condições, não há espaços para reflexão e discussão. Esse quadro se repete no Ensino Superior. Mas, também é no Ensino Superior que se mantém a crença de que, pelo fato de os alunos serem adultos, não ser necessário utilizar outros métodos e estratégias para auxiliar no desenvolvimento das potencialidades dos estudantes. É com foco em uma proposta diferenciada para a sala de aula, colocando o aluno como agente ativo da sua aprendizagem, que um trabalho investigativo pode colaborar para se conduzir discussões produtivas, propiciando uma aprendizagem mais efetiva.

Ponte (2003, p. 2) ressalta que existem muitas perspectivas sobre o que é investigar, entretanto, em sua ótica, "investigar, não é mais do que procurar conhecer, procurar compreender, procurar encontrar soluções para os problemas com qual nos deparamos." Para ele, "trata-se de uma capacidade de primeira importância para todos os cidadãos e que deveria permear todo trabalho da escola, tanto dos professores como dos alunos".

A investigação matemática se volta para a condução de um ensino e aprendizagem nos quais situações-problema são apresentadas para os alunos e estes são levados a pensar, conjecturar, questionar, testar suas hipóteses, discutir com seus pares, desenvolvendo sua autonomia, o espírito crítico, tendo o professor como condutor e reorganizador desse pensar, quando se fizer necessária a sua intervenção. É necessário "dar ao aluno a responsabilidade de descobrir e de justificar as suas descobertas." (PONTE, 2003, p. 12). Desse modo, o professor possibilita que a aprendizagem se torne significativa. Então, se há o desejo de que "os alunos desenvolvam plenamente as suas competências matemáticas e assumam uma visão alargada da natureza desta ciência, então as tarefas de exploração e investigação têm de ter um papel importante na sala de aula". (PONTE, 2003, p.12). Para nós, é ainda mais viável no Ensino Superior. 
Para se proceder a uma investigação, dentro dessa proposta, não é necessário partir de situações muito complexas ou problemas complicados, até porque os nossos alunos não estão habituados em proceder desta forma, pois, normalmente, estão acostumados a serem os receptores de conhecimentos.

A atividade de investigação deve ser desenvolvida atravessando três fases que se constituem:

(i) - introdução da tarefa, em que o professor faz a proposta à turma, oralmente ou por escrito; (ii) - realização da investigação, individualmente, aos pares, em pequenos grupos ou com toda a turma, e (iii) - discussão dos resultados, em que os alunos relatam aos colegas o trabalho realizado. Essas fases podem ser concretizadas de muitas maneiras. (...) aquela que tem vindo a ser mais utilizada pelos professores: uma pequena introdução, seguida da realização da investigação, em pequenos grupos e, finalmente, a discussão dos resultados, em grande grupo. (PONTE, BROCARDO, OLIVEIRA, 2013, p. 25).

Deste modo, é necessário reforçar alguns passos a serem seguidos dentro da metodologia da investigação matemática: primeiramente, o reconhecimento do problema proposto; a etapa de discussões, escolha das estratégias a serem seguidas; a fase de desenvolvimento e formulação de conjecturas, o momento em que se procedem testes, provas e validação das conjecturas; o estágio de socialização e discussão dos resultados.

Ressaltamos que, apesar de as investigações matemáticas envolverem "procedimentos e representações matemáticas", realmente, "o que mais fortemente as caracteriza é este estilo de conjectura-teste-demonstração", como destacam Ponte, Brocardo e Oliveira (2013, p. 10). Esses autores afirmam que, em uma atividade investigativa, é imprescindível que o docente fique atento ao trabalho dos alunos, verificando se compreenderam a tarefa, como estão procedendo, pois podem ocorrer momentos nos quais os alunos se fixam em encontrar a resposta para o que foi proposto, se apartando do propósito da atividade dentro do caráter investigativo.

O papel do professor é fundamental para que o desenrolar da atividade seja produtivo. Ele deve orientar e fazer perguntas ou observações no sentido de 
favorecer que os alunos reflitam sobre os seus procedimentos, conjecturas e conclusões, avaliando os resultados, sem, contudo, direcionar ou interferir nas resoluções dos alunos. Além disso, um pré-requisito primordial é que o professor estabeleça um ambiente propício para o desenvolvimento das tarefas, fazendo com que sejam respeitadas as opiniões de cada um, estimulando a comunicação entre os componentes do grupo, socializando as conclusões com a participação de todos e promovendo a discussão dos resultados.

\section{As TICs no processo de ensino/aprendizagem}

O século passado assistiu ao florescer de novas tecnologias, como a televisão, o computador e a Internet, que conduziram os educadores a utilizarem tais tecnologias nas escolas objetivando um ensino mais atrativo e uma aprendizagem calcada em outros recursos. A partir da década de 1990, surge uma nova terminologia no meio educacional: TICs (Tecnologia da Informação e Comunicação) - estas resultaram da fusão das tecnologias de informação, envolvendo a aquisição, o armazenamento, o processamento e a distribuição da informação por meios eletrônicos e digitais (FIORENTINI e LORENZATO, 2012).

Borba (2011) assinala que "os ambientes computacionais condicionam as ações quando se tem que resolver um problema matemático". A questão do componente visual, necessário, muitas vezes, na Matemática, é favorecida com a utilização de softwares educacionais. Quando o professor conduz o processo de ensino/aprendizagem tendo como ferramenta auxiliar um software educacional, possibilita que os alunos possam realizar investigações e experimentações, desenvolvendo "suas ideias a ponto de criarem conjecturas, validá-las e levantar subsídios para a elaboração de uma demonstração matemática". (BORBA, 2011, p. 4). Neste sentido, com a tecnologia computacional, é possível explorar outros aspectos que não seriam adequados ou muito demorados com apenas lápis e papel e mesmo com o auxílio de uma calculadora. A condução de uma atividade 
através de um software possibilita ao aluno simular e/ou checar determinadas conjecturas, abrindo espaço para novas reflexões e questionamentos.

Laudares e Lachini (200, p. 68) evidenciam a necessidade de se adequar novas metodologias fugindo do modelo tradicional pautado na exposição verticalizada de um saber pronto e acabado, o qual promove uma relação hierarquizada entre professor e aluno. Os autores, ainda, afirmam que:

... na mediação entre o saber e os métodos de estudo, estão os materiais e artefatos tecnológicos, utilizados pelos professores para viabilizar a didática. (...) Os meios, isto é, as ferramentas tecnológicas, nas mãos dos agentes, se tornam instrumentos para obtenção de resultados. A ferramenta - 0 computador - não tem inteligência, sensibilidade, emoção e nem intuição, características próprias dos sujeitos; somente quando usada por um sujeito é que a ferramenta se torna instrumento que pode explicitar as muitas qualidades de quem a usa. (LAUDARES e LACHINI, 2001,p.69).

Esses são pontos relevantes, uma vez que, muitos docentes utilizam a tecnologia pela própria tecnologia, ou seja, uma aula com o uso de slides, através de um equipamento multimídia, pode se caracterizar como uma aula expositiva tradicional verticalizada, na qual o protagonista continua sendo professor, sem a participação dos alunos. É necessário partir para uma metodologia em que a utilização das TICs se integre às aulas como um auxílio para os discentes, contribuindo para que seja possível, não apenas estudar temas tradicionais de maneira nova, mas, também, explorar ou experimentar tais temas e até abrir espaços para outros questionamentos e pesquisas, pela busca de novos temas.

O autor de livros de CDI, James Stewart (2014), faz um alerta em relação ao uso da tecnologia no processo educacional, chamando a atenção para o fato de que, ao se empregar a tecnologia, ampliam-se a importância e a necessidade de se entender com clareza os conceitos que implicitamente estão na tela. Nesse sentido, quando utilizados apropriadamente, com objetivos bem definidos pelo professor, computadores, smartphones e calculadoras gráficas, se tornam recursos adequados, que podem potencializar a descoberta e a compreensão de determinados conceitos, propriedades, teoremas, etc. pelos estudantes. Dentro 
dessa perspectiva, defendemos que ambientes informatizados podem contribuir de forma efetiva para o ensino/aprendizagem da Matemática.

Antigos e novos aplicativos, com finalidades educacionais, destinados à Matemática, são encontrados no mercado. Estão disponíveis alguns aplicativos gratuitos como Geogebra, Mathdraw, Winplot, dentre outros.

O Geogebra, que pode ser utilizado para o ensino de diversos conteúdos matemáticos do Ensino Fundamental ao Ensino Superior,

... é um software livre e pode ser usado facilmente como uma importante ferramenta para despertar o interesse pela busca do conhecimento matemático, principalmente com alunos dos ensinos fundamental e médio. Possibilita trabalhar de forma dinâmica em todos os níveis da educação básica, permitindo a abordagem de diversos conteúdos, especialmente os relacionados ao estudo da geometria e funções. (FANTI, 2010, p. 1).

Partimos da premissa de que muitos estudantes de cursos superiores já possuem um Smartphone, fazendo uso de várias de suas funcionalidades sem maiores problemas. Foi pensando em agregar a facilidade de se acessar a Internet, através de um Smartphone, sem a necessidade de deslocar uma turma para o laboratório de Informática, com as vantagens do aplicativo Geogebra devido sua funcionalidade e por ser bastante intuitivo - que elaboramos algumas atividades, congregando Smartphone e Geogebra, para introduzir o conceito de derivada, via uma abordagem geométrica.

\section{Utilizando vídeos nas aulas de Cálculo}

Atualmente, entre as opções tecnológicas utilizadas como ferramentas para o uso em espaços educativos, como as mídias sociais, temos, por exemplo, o YouTube, o qual vem ganhando mais espaço na educação. Já existem vários canais voltados para este fim.

Segundo Almeida et al. (2015), o YouTube, criado em junho de 2005, teve como fundadores Steve Chen, Chad Hurley e Jawed Karin. Inicialmente, foi 
concebido como um site de compartilhamento de vídeos, objetivando uma melhor qualidade neste serviço. Hoje em dia, é um site exclusivo, com amplo acesso, servindo um público superior a um bilhão de usuários em mais de 75 países.

No YouTube, é possível encontrar uma infinidade de vídeos sobre diversos temas e áreas de estudo, entre os quais estão disponíveis vídeos educacionais, que podem ser adequados para conduzir vários temas em sala de aula, seja na Educação Básica ou em cursos de nível superior.

Moran (1995, p. 27) sinaliza que o vídeo está umbilicalmente ligado à televisão, a um momento de lazer. Para este autor, o vídeo como recurso pedagógico traz, imperceptivelmente, um clima de entretenimento para sala de aula. Ele afirma que, vídeo, "na concepção dos alunos, significa descanso e não 'aula', o que modifica a postura e as expectativas em relação ao seu uso". Nessa linha de raciocínio, Moran assinala que é necessário "aproveitar essa expectativa positiva para atrair o aluno para os assuntos do planejamento pedagógico". Os professores podem se valer desse recurso midiático, aumentando o interesse dos alunos e proporcionando um melhor entendimento de determinados conteúdos.

O vídeo parte do concreto, do visível, do imediato, do próximo, que toca todos os sentidos. Mexe com o corpo, com a pele - nos toca e "tocamos" os outros, que estão ao nosso alcance, através dos recortes visuais, do close, do som estéreo envolvente. Pelo vídeo sentimos, experienciamos sensorialmente 0 outro, o mundo, nós mesmos. (MORAN, 1995, p. 28).

Em concordância com as potencialidades dos recursos audiovisuais, que podem ser direcionadas para finalidades educacionais, selecionamos alguns vídeos, dos quais, ao final, elegemos três deles, com o propósito de trazer o aluno para um ambiente mais atrativo, o qual despertasse um maior interesse e contribuísse para discutirmos aspectos não abordados em outras oportunidades.

O professor deve assistir aos vídeos, fazer sua seleção, dentro dos seus objetivos. O planejamento é fundamental. Aspectos dos vídeos podem legitimar determinado conteúdo a ser desenvolvido ou já trabalhado em sala de aula. A discussão sobre a temática dos vídeos, entre o grupo de discentes, com a 
mediação do professor, é importante para ressaltar determinados aspectos não percebidos pelos alunos e para elucidar pontos que não foram bem entendidos.

\section{0 produto educacional}

Como já foi mencionado, o nosso produto educacional se constituiu em caderno de atividades intitulado "A derivada e suas diferentes abordagens: uma proposta para a introdução do seu conceito"4. O material foi subdividido em três capítulos, abordando aspectos que consideramos relevantes, para auxiliar o professor de CDI a conduzir suas aulas apoiados em outras metodologias. No primeiro capítulo, trazemos alguns aspectos históricos do Cálculo Diferencial e Integral. No segundo, apresentamos os principais pontos para o desenvolvimento de uma Investigação Matemática e uma discussão sobre o uso das tecnologias. 0 último capítulo contém atividades, acompanhas de sugestões para o professor.

O produto educacional consiste em uma proposta para a introdução do conceito de derivada no sentido de subsidiar os professores no direcionamento de suas ações, transitando pelas vias das abordagens algébrica, geométrica e histórica. Inicialmente, são apresentadas duas atividades, subdivididas em várias tarefas, para introduzir o conceito de derivada, para cada uma delas, foi utilizada uma abordagem diferente - primeiramente, a algébrica e, a seguir, a geométrica. A abordagem histórica tem como suporte a apresentação de três vídeos. A cada tarefa, há observações e mensagens para o docente, no sentido de orientá-lo para acompanhar os alunos, quando a atividade deve ser realizada com o auxílio do professor, por exemplo.

Nossa sugestão, para o desenvolvimento das atividades, é que os alunos executem as tarefas em duplas ou, no máximo, em grupos de 4 integrantes.

\footnotetext{
${ }^{4} \mathrm{O}$ texto completo, relativo ao nosso produto educacional, pode ser encontrado no site do Mestrado em Ensino de Ciências e Matemática da PUC Minas, acessando o link: http://www1.pucminas.br/imagedb/documento/DOC DSC NOME ARQUI20180320143825.pdf
} 
A primeira atividade tem por objetivo trabalhar a abordagem algébrica da derivada, utilizando-se, para este fim, a Investigação Matemática, partindo da situação explicitada a seguir.

Um objeto é solto do topo de um prédio a $75 \mathrm{~m}$ de altura. Sabe-se que a altura $\boldsymbol{h}$ (em metros) do objeto em relação ao solo é dada em função do tempo $t$ (em segundos) pela função: $h(t)=-3 t^{2}+75$

Figura 1 - llustração referente à Atividade 1

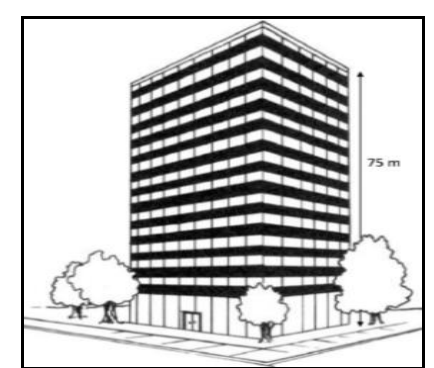

Fonte: http://static.hsw.com.br/gif/how-to-draw-buildings-49.jpg(adaptada)

Sabe-se que a velocidade média é obtida pela razão entre a distância percorrida e o tempo gasto em certo percurso, dada por:

$$
\begin{gathered}
V_{\text {média }}=\frac{D}{T} \Longrightarrow V_{\text {média }}=\frac{\Delta D}{\Delta T}=\frac{D_{f}-D_{0}}{T_{f}-T_{0}} \\
\text { Onde: }\left\{\begin{array}{l}
\Delta D=\text { variação da distância } \\
\Delta T=\text { variação do tempo } \\
D_{f}=\text { distância final } \\
D_{0}=\text { distância inicial } \\
T_{f}=\text { tempo final } \\
T_{0}=\text { tempo inicial }
\end{array}\right.
\end{gathered}
$$

Para esta situação inicial, elaboramos 13 tarefas, as quais não serão expostas neste artigo devido à sua extensão. As tarefas são conduzidas, a partir de conceitos básicos da Física, como a velocidade média. Espera-se que os alunos estabeleçam relações com o estudo de limite e, ao final da atividade, sejam capazes de calcular a velocidade num instante qualquer, conseguindo desenvolver o raciocício para generalizar o cálculo da velocidade instantânea. 
Na segunda atividade, constituída de 9 tarefas, o foco é a abordagem geométrica da derivada. Para atingir esse objetivo utiliza-se o aplicativo Geogebra instalado nos Smartphones dos alunos. Muitos estudantes universitários possuem Smartphones, colaborando para o desenvolvimento da atividade nos moldes planejados. Além disso, o trabalho será desenvolvido em duplas ou em grupo. 0 professor pode organizar os estudantes de modo que o número de Smartphones, com o aplicativo instalado, seja suficiente para o cumprimento de todas as etapas da atividade. A expectativa é de que, com a realização das tarefas, os alunos possam estabelecer relações com retas secantes e tangentes, assim como na primeira atividade, espera-se que também possam relacioná-la com o estudo de limites. Levando em consideração que, em geral, os alunos têm pouco ou nenhum conhecimento do aplicativo Geogebra, sugerimos que as três primeiras tarefas sejam realizadas com a mediação do professor. Cada atividade é apresentada, passo a passo, para auxiliar o docente que não tem experiência com o aplicativo.

A terceira atividade tem como finalidade tratar da abordagem histórica da derivada. Para cumprir esse intento, selecionamos três vídeos, disponíveis no YouTube, cujo principal objetivo foi legitimar as duas atividades anteriores, ou seja, fazer com que o aluno relacione, por meio dos vídeos apresentados, os problemas que originaram o Cálculo Diferencial, bem como, suas aplicações.

Nossa intenção é que o professor realize discussões a respeito do conteúdo dos vídeos, sob o viés da História da Matemática, no que diz respeito ao desenvolvimento do Cálculo Diferencial e Integral. É importante explorar a situação dada, sob os pontos de vista histórico e atual. Com a exibição dos vídeos e através dos debates sobre os mesmos, almeja-se que os alunos possam fazer conexões entre o passado e o presente.

O primeiro vídeo selecionado, com a duração aproximada de 25 minutos, $A$ História do Cálculo, uma produção da Open University, legendado em português, evidencia as ideias que desencadearam o surgimento do Cálculo e as pessoas que se dedicaram ao estudo contribuindo para grandes avanços na Matemática. 
Figura 2 - Cena do vídeo sobre a História do Cálculo

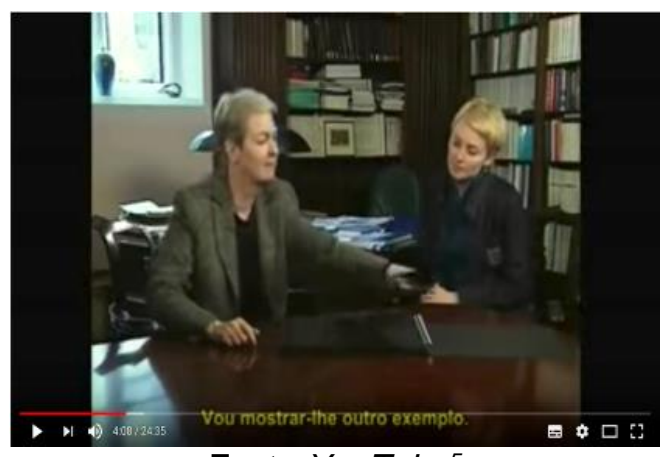

Fonte:YouTube ${ }^{5}$

O segundo vídeo proposto, Newton x Leibniz, tem duração aproximada de 5 minutos. Trata-se de uma animação que, de forma irreverente, traz a temática das possíveis "desavenças" entre Newton e Leibniz pelo reconhecimento da invenção do Cálculo. É um trabalho da seção "Grandes peleas de la ciencia", do Proyecto.G, um programa de televisão com fins educativos, emitido pelo Canal Encuentro, do Ministério de Educação da Argentina (LOPEZ, 2011).

Este vídeo, em especial, evidencia a importância da imagem como ferramenta no ensino, pois o áudio está em outro idioma (espanhol), porém, mesmo assim, a mensagem passada pelo vídeo se faz entender.

Figura 3 - Cena do vídeo de Newton x Leibniz

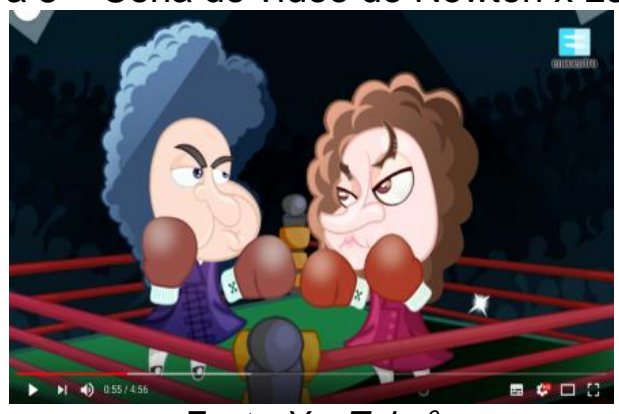

Fonte:YouTube ${ }^{6}$

O terceiro vídeo, com duração aproximada de 4 minutos, foi produzido por estudantes do curso de Engenharia Civil da UNEMAT - Universidade do Estado de Mato Grosso. Há uma breve apresentação da História do Cálculo e, em

\footnotetext{
${ }^{5}$ Link de acesso: https://www. YouTube.com/watch?v=6HI47rcOiAE

${ }^{6}$ Link de acesso: https://www.YouTube.com/watch?v=fOIPCSpCNVA
} 
seguida, são destacadas determinadas aplicações utilizadas atualmente. Nossa intenção, quanto ao uso deste vídeo, é trazer uma linguagem mais próxima dos discentes e que eles possam tomar conhecimento de aplicabilidades do Cálculo.

Figura 4 - Imagem do vídeo sobre as Aplicações do Cálculo

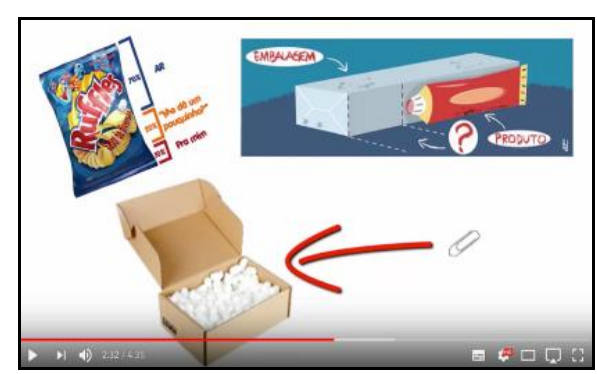

Fonte:YouTube ${ }^{7}$

\section{Sobre a aplicação do produto}

O produto foi aplicado num curso de extensão intitulado "Aprimoramento de Cálculo Diferencial: ressignificando o conceito de Derivada", promovido no Centro Universitário Newton Paiva ${ }^{8}$, destinado para os alunos dos cursos de Engenharia. Este curso teve a duração de 6 horas/aula, dividido em três dias consecutivos. Em cada dia, foi desenvolvida uma das três atividades apresentadas anteriormente. Todos os inscritos já tinham cursado o Cálculo Diferencial.

A primeira atividade contou com o pleno envolvimento dos participantes. Pudemos constatar que, ao concluírem a atividade, os alunos entenderam a diferença entre velocidade média e velocidade instantânea, bem como, sua importância e aplicabilidade no estudo de limites. Em momento algum, foi mencionada a palavra derivada no decorrer desta atividade, nem pelo professor, nem pelos alunos. Algo importante porque o nosso ensejo era que o conceito se consolidasse com a abordagem geométrica.

\footnotetext{
7 Link de acesso: https://youtu.be/1wcAzH4H1Bw

8 A instituição localiza-se em Belo Horizonte, Minas Gerais.
} 
A segunda atividade também contou com a participação efetiva dos alunos. Embora nunca tivessem utilizado o Geogebra, os participantes foram assimilando os comandos e conseguiram realizar as tarefas, atingindo os objetivos almejados.

Com a terceira atividade, ao exibirmos os vídeos, nos certificamos que os mesmos se constituíram em uma importante ferramenta. Os alunos elogiaram a sequência dos vídeos e os assuntos abordados.

Como havíamos previsto, os audiovisuais legitimaram as duas atividades realizadas anteriormente. Após assistirem aos vídeos, os alunos perceberam que o Cálculo que conhecemos hoje surgiu de dois grandes problemas: o problema da reta tangente e o problema das quadraturas. Eles também tiveram a oportunidade de saber um pouco mais sobre os personagens que contribuíram para 0 desenvolvimento do Cálculo. Desta forma, os alunos conseguiram correlacionar a primeira atividade, desenvolvida por eles, com os problemas de Newton relativos à velocidade (método das fluxões). A atividade 2 foi relacionada com um dos grandes problemas do Cálculo Diferencial, o problema da reta tangente. Verificamos que os vídeos ampliaram o conhecimento dos alunos, possibilitando a ligação do que foi desenvolvido nos dois primeiros dias do curso de extensão.

\section{Considerações finais}

Através do curso de extensão, foi possível averiguar que a investigação matemática é uma metodologia eficaz para um trabalho a partir das abordagens algébrica e geométrica da derivada. Para esta última, a utilização do Geogebra foi fundamental. A visualização das situações propostas nas tarefas, através do aplicativo, proporcionou uma maior apreensão do conceito, permitindo um avanço nas discussões. Em três dias, os alunos assimilaram mais concretamente 0 conceito de derivada do que, em um semestre, cursando a disciplina CDI.

Em relação à exibição dos vídeos, constatamos que realmente aproximam a aula a um momento de lazer, um momento de entretenimento, como afirma Moran (1995). Nesse ambiente, os alunos se mostraram mais interessados e 
receptivos para novas instruções e outras informações. Comprovamos que os recursos midiáticos se constituem em uma estratégia efetiva também para a aprendizagem do $\mathrm{CDI}$, agregando uma postura reflexiva sobre os temas tratados.

Através do depoimento dos alunos, das nossas observações e anotações realizadas durante a aplicação do produto, ficou claro que conduzir as aulas em um ambiente diferente do tradicional, recorrendo a Investigação Matemática, ao uso do celular em sala de aula, explorando aplicativos destinados ao ensino de Matemática e trazer alguns pontos da História da Matemática, por meio de vídeos, contribuiu para alcançar os nossos objetivos. Estes fatos nos levam a crer que, o nosso produto educacional pode servir de apoio e direcionamento para os professores de CDI, colaborando positivamente para a introdução do conceito de derivada para os alunos ingressantes em vários cursos na área de Ciências Exatas. As atividades e tarefas podem ser modificadas e outros vídeos exibidos, de acordo com os objetivos dos professores.

Terminamos, registrando as palavras de André Chervel (1990, p. 199): "a teoria, os exercícios se renovam: os novos métodos" tiveram "lugar mais ou menos no início do século XX" e, "desde então eles não mudaram fundamentalmente. Nessas diversas evoluções, é a transformação do público escolar que obrigou a disciplina a se adaptar". A busca por novos caminhos se faz necessária.

\section{Referências}

ALMEIDA, Ítalo D.; SILVA, Jeissy C. B.; SILVA JUNIOR, Sandoval A.; BORGES, Luzineide M. Tecnologias e Educação: o uso do YouTube na sala de aula. In: CONGRESSO NACIONAL DE EDUCAÇÃO, 2., 2015, Campina Grande. Anais... 2015.

ANDRÉ, Selma Lopes da Costa. Uma proposta para o ensino do conceito de derivada no Ensino Médio. 2008. 232f. Dissertação (Mestrado em Ensino de Matemática) - Universidade Federal do Rio de Janeiro, Rio de Janeiro, 2008.

BARBOSA, Marcos Antônio. O insucesso no ensino e aprendizagem na disciplina de Cálculo Diferencial e Integral. 2004. 101f. Dissertação (Mestrado em Educação) Pontifícia Universidade Católica do Paraná, Curitiba, 2004. 
BISOGNIN, Eleni; BISOGNIN, Vanilde. Análise do desempenho dos alunos em formação continuada sobre a interpretação gráfica das derivadas de uma função. Educação Matemática Pesquisa, São Paulo, v. 13, n. 3, p. 509-526, 2011.

BORBA, Marcelo Carvalho. Educação Matemática à distância online: balanço e perspectivas. In: CONFERÊNCIA INTERAMERICANADE EDUCAÇÃO MATEMÁTICA, 13., 2011. Anais... Recife: Brascolor Gráfica e Editora LTDA, 2011. p. 1-9.

BROCARDO, Joana. As investigações na aula de Matemática: um projecto curricular no 8 $^{\circ}$ ano. 2001. 621 f. Tese (Doutorado em Educação) - Universidade de Lisboa, Lisboa, 2001.

CHERVEL, André. Histórias das Disciplinas Escolares: reflexões sobre um campo de pesquisa. Teoria e Educação, Porto Alegre, n. 2, p. 177-229, 1990.

FIORENTINI, Dario; LORENZATO, Sérgio. Investigação em educação matemática: percursos teóricos e metodológicos. 3. ed.ver. Campinas, SP: Autores Associados, 2012.

FANTI, Ermínia de Lourdes Campello. Utilizando o software Geogebra no ensino de certos conteúdos matemáticos. Disponível em: $\leq \mathrm{http}: / /$ www.mat.ufpb.br/bienalsbm arquivos/Conferencias\%20Apresentadas/C\%203.pdf>. Acesso em: 12 jun. 2017.

FERREIRA, Allan Silva; ZUIN, Elenice de Souza Lodron; OLIVEIRA, Lídia Maria Luz. Paixão Ribeiro de. A derivada e suas diferentes abordagens: uma proposta para a introdução do seu conceito. Belo Horizonte: PUC Minas, 2017.

FROTA, Maria Clara Resende. Ambientes que favorecem a visualização e a comunicação em Cálculo. In: FROTA, Maria Clara R.; BIANCHINI, Bárbara Lutaif; CARVALHO, Ana Márcia F. Tucci. (Orgs.). Marcas da Educação Matemática no Ensino Superior. Campinas: Papirus, 2013. p. 61-88.

FROTA, Maria Clara R. Investigações na sala de aula de Cálculo. In: REUNIÃO ANUAL DA ASSOCIAÇÃO NACIONAL DE PÓS-GRADUAÇÃO E PESQUISA EM EDUCAÇÃO MATEMÁTICA, 29., 2006, Caxambu. Anais... (CD Rom). ANPED, 2006. p. 1-14.

GARZELLA, Fabiana A. C. A disciplina de Cálculo I: análise das relações entre as práticas pedagógicas do professor e seus impactos nos alunos. 2013. 257f. Tese (Doutorado em Educação). Universidade Estadual de Campinas, Campinas, SP, 2013.

IGLIORI, Sônia B. C. Considerações sobre o ensino de Cálculo e um estudo sobre números reais. In: FROTA, Maria Clara. R.; NASSER, Lílian. (Org.). Educação Matemática no Ensino Superior: pesquisas e debates. Recife: SBEM, 2009. p.11-26.

LAUDARES, João Bosco; LACHINI, Jonas. O uso do computador no ensino de matemática na graduação. In: LAUDARES, João Bosco; LACHINI, Jonas (Orgs.).

Educação Matemática: a prática educativa sob o olhar de professores de Cálculo. Belo Horizonte: FUMARC, 2001. p. 68-88. 
LIMA, Airlan A. N. Introduzindo o conceito de derivada a partir da ideia de variação. 2012. 113 f. Dissertação (Mestrado em Ensino de Física) - Universidade Estadual da Paraíba, Campina Grande, 2012.

LOPEZ, Vanina Soledad. Ciencia para descotillarse: recursos humorísticos en la TV publica argentina. El caso de Proyecto G. Razón y palabra, n. 75, feb./abr. 2011.

MORAN, José Manuel. O vídeo na sala de aula. Revista Comunicação e Educação, n.2, p. 27-35, jan. /abr.1995.

OLIMPIO JÚNIOR, Antonio. Compreensões de conceitos de Cálculo Diferencial no primeiro ao de Matemática: uma abordagem integrando a oralidade, escrita e informática. 2006. 264f. Tese (Doutorado em Educação Matemática) - Universidade Estadual Paulista, Instituto de Geociências e Ciências Exatas, Rio Claro, 2006.

PONTE, João Pedro. Investigar, ensinar e aprender. In: PROFMAT, 16., 2003, Lisboa, Portugal. Actas... (CD Rom). Lisboa: APM, 2003.

PONTE, João Pedro; BROCARDO, Joana; OLIVEIRA, Hélia. Investigações Matemáticas na sala de aula. Belo Horizonte: Autêntica, 2013.

REIS, Frederico S. Rigor e intuição no ensino de Cálculo e Análise. In: FROTA, Maria Clara R.; NASSER, Lílian (Orgs.). Educação Matemática no Ensino Superior: pesquisas e debates. Recife: SBEM, 2009. p. 81-97.

WROBEL, Julia Schaetzle; ZEFERINO, Marcus Vinicius Casoto; CARNEIRO, Teresa Cristina Janes. Um mapa do ensino de cálculo nos últimos 10 anos do COBENGE. In: CONGRESSO BRASILEIRO DE ENSINO DE ENGENHARIA, 41., 2013, Gramado. Anais... Gramado: UFRGS, 2013.

ZUIN, Elenice de Souza Lodron. História da Matemática: considerações no campo educacional. In: ENCONTRO MINEIRO DE EDUCAÇÃO MATEMÁTICA, 3, 2003, Belo Horizonte. Anais... (CD-Rom). Belo Horizonte: SBEM-MG, 2003. 